\title{
Afforestation or intense pasturing improve the ecological and economic value of abandoned tropical farmlands
}

Thomas Knoke ${ }^{1}$, Jörg Bendix ${ }^{2}$, Perdita Pohle ${ }^{3}$, Ute Hamer ${ }^{4} \uparrow$, Patrick Hildebrandt ${ }^{1}$, Kristin Roos $^{5}$, Andrés Gerique ${ }^{3}$, María L. Sandoval ${ }^{6}$, Lutz Breuer ${ }^{7}$, Alexander Tischer ${ }^{4}$, Brenner Silva ${ }^{2}$, Baltazar Calvas ${ }^{1}$, Nikolay Aguirre ${ }^{8}$, Luz M. Castro9 ${ }^{9}$ David Windhorst ${ }^{7}$, Michael Weber ${ }^{1}$, Bernd Stimm ${ }^{1}$ Sven Günter ${ }^{10} \dagger$, Ximena Palomeque ${ }^{1}$, Julio Mora', Reinhard Mosandl ${ }^{1} \&$ Erwin Beck ${ }^{5}$

Increasing demands for livelihood resources in tropical rural areas have led to progressive clearing of biodiverse natural forests. Restoration of abandoned farmlands could counter this process. However, as aims and modes of restoration differ in their ecological and socio-economic value, the assessment of achievable ecosystem functions and benefits requires holistic investigation. Here we combine the results from multidisciplinary research for a unique assessment based on a normalization of 23 ecological, economic and social indicators for four restoration options in the tropical Andes of Ecuador. A comparison of the outcomes among afforestation with native alder or exotic pine, pasture restoration with either low-input or intense management and the abandoned status quo shows that both variants of afforestation and intense pasture use improve the ecological value, but low-input pasture does not. Economic indicators favour either afforestation or intense pasturing. Both Mestizo and indigenous Saraguro settlers are more inclined to opt for afforestation.

\footnotetext{
${ }^{1}$ TUM School of Life Sciences Weihenstephan, Technische Universität München, 85354 Freising, Germany. ${ }^{2}$ Laboratory for Climatology and Remote Sensing (LCRS), Faculty of Geography, University of Marburg, 35032 Marburg, Germany. ${ }^{3}$ Institute of Geography, University of Erlangen-Nürnberg, 91058 Erlangen, Germany. ${ }^{4}$ Institute of Soil Science and Site Ecology, Dresden University of Technology, 01737 Tharandt, Germany. ${ }^{5}$ Department of Plant Physiology and Bayreuth Centre of Ecology and Environmental Research, University of Bayreuth, 95440 Bayreuth, Germany. ${ }^{6}$ Departamento de Desarrollo Ambiente y territorio, Facultad Latinoamericana de Ciencias Sociales, FLACSO, 170516 Quito, Ecuador. ${ }^{7}$ Institute for Landscape Ecology and Resources Management, Justus Liebig University Giessen, 35392 Giessen, Germany. ${ }^{8}$ Biodiversity, Forestry and Ecosystem Services Research Program, National University of Loja, 110101 Loja, Ecuador. ${ }^{9}$ Departamento de Economía, Universidad Técnica Particular de Loja, 1101608 Loja, Ecuador. ${ }^{10}$ Tropical Agricultural Research and Higher Education Center (CATIE), 7170 Turrialba-Cartago, Costa Rica. † Present address: Institute of Landscape Ecology, University of Muenster, 48149 Münster, Germany (U.H.) Thünen-Institut, 21031 Hamburg, Germany (S.G.). Correspondence and requests for materials should be addressed to T.K. (email: knoke@forst.wzw.tum.de).
} 
$\mathrm{D}$ ecreasing agricultural yields and increasing national and global competition ${ }^{1,2}$ force farmers to abandon less productive lands and either clear more pristine forest for agriculture or give up agriculture as the basis of their livelihoods. Reclaiming abandoned areas to resume production is rarely considered a worthwhile alternative. Field et al. ${ }^{3}$ estimated that $386 \mathrm{M}$ ha of abandoned lands worldwide have the potential for renewed productive use.

Re-utilization could not only mitigate the increasing pressures on natural forest, but could also help to alleviate poverty by improving food security ${ }^{4}$, to promote rural socio-economic development ${ }^{5}$ and to lower rural outmigration. Sustainability research must, therefore, investigate strategies to recover abandoned lands 6 .

Existing approaches to the problem of restoration have largely been focused on afforestation attempts and either their ecological $^{7}$, economic ${ }^{8}$ or social ${ }^{9}$ consequences. A more holistic, but thus far unrealized, ideal of research into the benefits humans receive from ecosystems should provide biophysically realistic ecosystem data and models, consider local trade-offs, recognize off-site effects and involve stakeholders ${ }^{10}$. Moreover, to promote sustainable future land use, not only afforestation but also restoration of agricultural potential should be considered. Consequently, scientifically responsible decision support requires multidisciplinary long-term research that supports reliable parameterization of customized models.

Although benefit-specific ecosystem services are generally narrowly defined as components of nature that are directly enjoyed, consumed or used as final products and services ${ }^{11}$, we use a broader approach to assess the capacity of natural processes and components of restoration options to provide goods and services $^{12}$. Our ecological indicators thus quantify ecosystem functions. Following the classification by Boyd and Banzhaf ${ }^{11}$, our socio-economic indicators are estimates of the benefits farmers may obtain from each restoration option.

In the tropical Andes of southern Ecuador, clearing of natural forest commonly follows the abandonment of pastures and thus represents a widespread example of unsustainable land use ${ }^{13,14}$. This practice occurs mostly in tropical mountain regions beginning at $1,500 \mathrm{~m}$ altitude and continuing up to the tree line ${ }^{15-17}$, in Latin America and also elsewhere ${ }^{18,19}$. In our study area, abandoned pastures have already grown to $35 \%$ of the total pasture area ${ }^{20}$. One major reason for this adverse development is the invasion of weeds-mainly tropical bracken fern, which is resistant to burning-the most common local weed control tool $^{21}$. The use of fire begins with the clearing of the natural forest and is regularly applied thereafter for weed control and pasture rejuvenation. In this topographically diverse landscape with highly fragmented vegetation, productive alternatives to leaving areas abandoned are of utmost ecological and socio-economic importance ${ }^{22}$. This applies particularly to southern Ecuador where the native mountain forests contribute significantly to the outstanding biodiversity ${ }^{23}$ (Supplementary Methods). In the present work, we evaluate four different options for reintegrating abandoned pastures into the production process. The results of experiments-some running as long as 15 yearsshow that both afforestation ${ }^{13}$ and restoration of pasture ${ }^{24}$ ('repasturization') are feasible alternatives to leaving land abandoned. However, these results also suggest that large financial inputs as compared with the business-as-usual (BAU) option-pasturing after clearing of natural forest-are necessary to establish the restoration options.

The use of appropriate indicators is pivotal to answering policy-relevant questions concerning the potential benefits that people may obtain from ecosystems ${ }^{25}$. The establishment of standardized methods allows comparisons of ecosystem functions and benefits if they are adjusted for location and to address specific problems. However, the integration of multiple functions and benefits into a general assessment is still problematic and are relatively uncommon in the literature ${ }^{25}$. Our novel evaluation approach to quantifying and assessing the ecosystem functions and benefits of different land-use options is an attempt to solve these problems. It uses normalized indicators to make various ecosystem functions and benefits comparable, which, in this study, proves itself to be a robust method even under rigorous sensitivity assessments. We show that averaged ecological and socio-economic indicators are highly positively correlated. Afforestation ranks highest both from the ecological and the socio-economic points of view, followed by repasturization with subsequent intense pasturing. However, the options for land restoration provide relatively low short-term socio-economic benefits for farmers when compared with the BAU land use (pasturing after forest clearing). Because of this, to successfully promote restoration options as a way to relieve the pressure on biodiverse natural forests, a compensation amount of up to US\$ $180 \mathrm{ha}^{-1}$ per year may be necessary.

\section{Results}

Assessing ecosystem functions and benefits. We will first present our approach for assessing multiple ecosystem functions and benefits of five land-use options (Table 1). Next, we justify the selected indicators and briefly illustrate the process of assessing the various restoration options using data from our study area. Each indictor subsection concludes with highlighting the results of general importance for that indicator.

We use 23 indicators to characterize four key elements of 'Ecological Functions' and four key elements of 'Socio-economic Benefits' (Table 2), to thoroughly assess the potential ecosystem functions and benefits provided by the land-use options investigated. The indicators include supporting (biomass production and soil quality) and regulating functions (carbon, climate and hydrology), as well as provisioning (timber and food) and social benefits (acceptance by the local people), and are meant to

Table 1 | Characterization of the land-use options investigated.

\begin{tabular}{|c|c|c|c|}
\hline Land-use option & Land preparation & Establishment & Management \\
\hline $\begin{array}{l}\text { Alnus: afforestation with native Alnus acuminata } \\
\text { Pinus: afforestation with exotic Pinus patula }\end{array}$ & $\begin{array}{l}\text { Initial removal of weeds } \\
\text { (bracken) }\end{array}$ & $\begin{array}{l}\text { 1,111 Trees per } \\
\text { hectare }\end{array}$ & $\begin{array}{l}\text { Weed control in years } 1 \text { and } 2,2 \text { thinning } \\
\text { campaigns (years } 12 \text { and 16) }\end{array}$ \\
\hline $\begin{array}{l}\text { Intense pastures: repasturization with intense } \\
\text { management after chemical weed control }\end{array}$ & $\begin{array}{l}9 \text { Months with } 3 \text { recurrent } \\
\text { herbicide applications }\end{array}$ & As above & $\begin{array}{l}3 \text { Grazing rounds/year } \\
3 \text { Fertilization campaigns/year }\end{array}$ \\
\hline
\end{tabular}


Table 2 | Categories, key elements and associated indicators, data sources.

\begin{tabular}{|c|c|c|c|}
\hline Categories & Key elements & Indicators & Data source \\
\hline \multirow[t]{4}{*}{$\begin{array}{l}\text { Ecological } \\
\text { functions }\end{array}$} & $\begin{array}{l}\text { Carbon } \\
\text { relationships }\end{array}$ & $\begin{array}{l}\text { Biomass production, carbon in planta, } \\
\text { soil organic carbon }\end{array}$ & $\begin{array}{l}\text { Afforestation: statistical regression models, parameters } \\
\text { estimated from field data; pastures and abandoned pastures: } \\
\text { field data plus process-based model for annual below-ground } \\
\text { biomass production }\end{array}$ \\
\hline & Climate regulation & Evapotranspiration, momentum flux & $\begin{array}{l}\text { Process-based models, most model parameters estimated from } \\
\text { field data }\end{array}$ \\
\hline & $\begin{array}{l}\text { Hydrological } \\
\text { regulation }\end{array}$ & $\begin{array}{l}\text { Surface flow, groundwater recharge, area- } \\
\text { specific discharge }\end{array}$ & \\
\hline & Soil quality & $\begin{array}{l}\mathrm{pH} \text {, soil organic carbon, base saturation, carbon } \\
\text { in microbial biomass, } \mathrm{C} \text {-mineralization, } \\
\mathrm{N} \text {-mineralization, } \mathrm{PO}_{4}-\mathrm{P}\end{array}$ & Field data \\
\hline \multirow[t]{2}{*}{$\begin{array}{l}\text { Socio- } \\
\text { economic } \\
\text { benefits }\end{array}$} & $\begin{array}{l}\text { Net present value } \\
\text { Payback period }\end{array}$ & $5 \%$ and $8 \%$ discount rates & $\begin{array}{l}\text { Evaluation of timber and cattle products with market prices and } \\
\text { costs (obtained from household surveys supplemented by data of } \\
\text { the Food and Agriculture Organization of the United Nations) }\end{array}$ \\
\hline & $\begin{array}{l}\text { Saraguro } \\
\text { preference } \\
\text { Mestizo } \\
\text { preference for } \\
\text { each land-use } \\
\text { option }\end{array}$ & $\begin{array}{l}\text { Saraguros asked with and without the } \\
\text { option of subsidies } \\
\text { Mestizos asked with and without the } \\
\text { option of subsidies }\end{array}$ & Standardized questionnaires \\
\hline
\end{tabular}

represent a comprehensive set of indicators of the potential capacity for the various restoration options to generate benefits from ecosystems ${ }^{26}$.

Social acceptance serves here as an indicator of the cultural benefit, for example, the compatibility with traditional livelihoods, as well as their contribution to landscape aesthetics or preserving cultural heritage. Although people often consider both provisioning and regulating functions when expressing their preferences, they also tend to include intangible values of land use, which are largely determined by tradition, experience and personal preference. However, as intangible cultural values are impossible to measure in ecological units, social acceptance can be used as a meaningful proxy for cultural ecosystem benefits, which are often ignored in existing approaches to assessing ecosystem services ${ }^{27}$.

We normalized every indicator by considering the relative position of each value in the range between the real minimum (referred to as $0 \%$ ) and real maximum values (100\%) ('min-max normalization') to obtain a unitary performance index, $P_{\mathrm{i}}$. The minimum is considered to be the least and the maximum the most desirable value. Other approaches have used a hypothetical indicator value of zero as the minimum ${ }^{28,29}$, although zero is rarely included in the set of possible results. For example, as plants always store carbon, assigning a value of zero carbon to any kind of vegetation is not realistic. Moreover, our min-max normalization allows us to use indicators for which negative values are possible (for example, economic indicators). To combine indicators into a higher-ranked category-the key element index $P_{\mathrm{k}}$-we averaged the $P_{\mathrm{i}}$ values. We then formed the ecological and socio-economic index value of each land-use option, $W P_{\mathrm{o}}$, by calculating the average of its $P_{\mathrm{k}}$ indices. We applied the 'more is better' principle for most indicators. However, for 'overland flow' and 'payback period', the 'less is better' principle was used. This means that applying our scheme requires some local experience to form a meaningful assessment of each indicator.

Finally, we use sensitivity scenarios to test the robustness of our assessment approach. In one scenario, we account for the size of the differences by weighting the indicator values by their relative range of variation (objective weighting), because through our normalization, even small differences in indicator values are scaled between 0 and $100 \%$. In another scenario, we test the impact of uncertainty by using both pessimistic and optimistic estimates (based on 95\% confidence limits). After the pessimistic and optimistic indicators are normalized to create performance indices, their range is used to evaluate the robustness of our assessment system. The results of the uncertainty analyses are described in 'Synopsis and sensitivity of indices'.

Ecological indicators. Carbon relationships characterize the uptake and accumulation of carbon-a primary ecosystem function that is a pivotal part of provisioning (for example, fodder for cattle or timber), regulating (storage of atmospheric carbon) and life supporting (organic matter to improve soil quality) ecosystem services. We use three indicators for this assessment: biomass production, whole plant-cover carbon accumulation and soil organic carbon (Table 3 and Supplementary Tables 1 and 2). Carbon relationships for abandoned pastures assume equilibrium between production and death of bracken leaves and rhizomes ${ }^{30}$. For the tree plantations (Alnus or Pinus, see Supplementary Methods and Supplementary Tables 3 and 4), average values for biomass production over a 20 -year period are computed, which account for losses from thinning and mortality.

Annual biomass production of bracken fern on abandoned pastures is the second highest among the options investigated. Thus, owing to the combination of the carbon present in this biomass and the organic carbon of the soil, abandoned areas rank intermediate in terms of total C-sequestration. The annual (20year average) biomass production in the tree plantations is relatively low (see Supplementary Methods and Supplementary Fig. 1 for discussion). The corresponding average total carbon stocks in planta are slightly lower than those in the abandoned areas. However, when carbon in the accumulating litter layer is considered (Supplementary Table 3), total carbon sequestration in the tree plantations is in the same range as that calculated for abandoned pastures (Table 3). In both pasture types, Setaria is planted after bracken control. A nearly homogeneous grass canopy has been achieved after 1.5 years. In the 'low-input' variant, nutrient shortage strongly limits growth, even before weeds come up. After two rounds of (simulated) grazing, equilibrium biomass production is established with an above- 
to below-ground average ratio of 0.05 . Owing to the very low $\mathrm{C}$ content in the standing above-ground biomass, C-sequestration potential in low-input pasture is the lowest of all the land-use options investigated. In contrast, fertilization of pastures in the high-input alternative results in an almost two-fold (over lowinput pasture) and in some cases even a six-fold increase (over tree plantations) in above-ground biomass production. All of the grass leaf biomass except the basal $20 \mathrm{~cm}$ is removed in each of the three (simulated) grazing rounds.

The annual biomass production differs among the five ecosystem alternatives by a factor of 6.5 and plant-bound carbon by a factor of 2.6. The amount of carbon sequestered by each is similar $(\Delta \sim 20 \%)$ due to the soil-bound fraction, which is high in all options. Because of high annual biomass production, the indices for 'Carbon relationships' are high for intense pasturing, moderate for both abandoned land and Pinus plantation, and low for low-input pasture and Alnus plantation.

Climate regulation is another important function of ecosystems, and the type and structure of the ecosystem directly influences the nature of surface-atmosphere exchanges. Thus, large-scale land-use changes elicit changes in both microclimate and the climate regulation function of an ecosystem ${ }^{31}$. The main drivers of this are changes in energy balance, surface roughness and evapotranspiration (ET), all of which link atmospheric to hydrological functions ${ }^{32}$. Here we calculate water and momentum fluxes (turbulence production, an important landatmosphere feedback parameter) for a 20 -year period using the coupled SoBraCo-catchment modelling framework (CMF) ${ }^{33}$ (see Methods and Supplementary Methods), to derive indicators for the intensity of surface-atmosphere exchanges.

The main components of microclimate, ET and turbulence production (M-flux, or the sum of zonal and meridional momentum fluxes) differ among the various land-use options (Table 4).
We find ET, the majority of which is plant transpiration, to be similar in the two types of tree plantation and significantly higher here than in the abandoned area. Periodic removal of biomass from the active pasture options leads to a decrease in transpiration, resulting in an overall ET lower than that in the tree plantations, but still higher than that of the abandoned pasture. Turbulence production is very high in tree plantations, whereas re-established pasture performs similarly to abandoned pasture.

Altogether, the tree plantations mimic the climate regulation function of a natural forest better than the options without trees. Afforestation with the broadleaf Alnus is even more effective in this regard than with Pinus.

Hydrological regulation performances of the various restoration options are crucial elements in assessing their potential for mitigating the adverse effects of water (such as erosion) but also in controlling the quantitative supply of water. We simulate below-ground water cycles using the well tested $\mathrm{CMF}^{34}$ (see Methods, Supplementary Methods and Supplementary Tables 5 and 6). Similar to the ambiguous effects that ecohydraulic processes can have on hydrological ecosystem services ${ }^{25}$, the investigated indicators might have a positive or a negative effect. For example, discharge (water volume) is a resource for hydropower ${ }^{35}$, and water that quickly leaves a system via overland flow and seepage prevents soils from becoming waterlogged. Therefore, rapid movement of water through the system can be considered positive. In contrast, seepage flow can also leach nutrients and overland flow can cause erosion, resulting in a negative effect from this indicator. To make our assessment more easily transferrable to sites with different objectives (high discharge or minimizing leaching/erosion), we calculate two separate indicators. The first indicator $\left(P_{\mathrm{k} 1}\right)$ combines a positive effect (discharge) and a negative effect (overland flow), while the second $\left(P_{\mathrm{k} 2}\right)$ considers both factors to be negative (Table 5).

Table 3 | Rating of the key element 'Carbon relationships' (indicator value \pm s.e.m.)^.

\begin{tabular}{|c|c|c|c|c|c|c|c|c|c|}
\hline \multirow[t]{2}{*}{ Land-use option } & \multicolumn{2}{|c|}{ Annual biomass production } & \multicolumn{6}{|c|}{ Carbon stocks } & \multirow{2}{*}{$\begin{array}{c}\text { Carbon relationships } \\
\qquad \boldsymbol{P}_{\mathbf{k}}\end{array}$} \\
\hline & (Mg ha ${ }^{-1}$ per year) & $P_{\mathbf{i}}$ & \multicolumn{2}{|c|}{ Carbon in planta ${ }^{\dagger}$} & \multicolumn{2}{|c|}{ Soil organic carbon } & \multicolumn{2}{|c|}{ Total carbon } & \\
\hline Abandoned pastures & $31.8 \pm 4.8$ & 57 & $33.0 \pm 2.9$ & 100 & $87.3 \pm 5.3$ & 0 & $120.3 \pm 6.9$ & 85 & 52 \\
\hline Pinus & $8.9 \pm 0.4$ & 3 & $29.6 \pm 1.4$ & 83 & $93.5 \pm 4.6$ & 69 & $123.1 \pm 4.8$ & 100 & 52 \\
\hline Low-input pastures & $26.5 \pm 4.4$ & 44 & $12.5 \pm 1.2$ & 0 & $91.8 \pm 4.9$ & 50 & $104.4 \pm 6.5$ & 0 & 32 \\
\hline Intense pastures & $50.0 \pm 2.3$ & 100 & $25.8 \pm 3.4$ & 65 & $96.3 \pm 5.1$ & 100 & $122.2 \pm 5.5$ & 95 & 88 \\
\hline
\end{tabular}

*Estimates for tree plantations from statistical-based regression models parameterized with field data; for pastures, all data from field measurements except annual below-ground biomass production which was estimated by the process-based model SoBraCo 33 with parameters derived from field data.

which was estimated by the proc

$\dagger$ Averaged over a 20 -year period.

†Organic layer and mineral top soil $(0-20 \mathrm{~cm}$ depth).

Table 4 | Rating of the key element 'Climate regulation' (indicator value \pm s.e.m.)^.

\begin{tabular}{|c|c|c|c|c|c|}
\hline \multirow[t]{2}{*}{ Land-use option } & \multicolumn{2}{|c|}{ ET } & \multicolumn{2}{|c|}{ MF } & \multirow[t]{2}{*}{$\boldsymbol{P}_{\mathrm{k}}$} \\
\hline & $(\mathrm{mm})$ & $P_{i}$ & $\left(\mathrm{~kg} \mathrm{~m}^{-1} \mathrm{~s}^{-2}\right)$ & $P_{i}$ & \\
\hline Abandoned pastures & $928 \pm 3.80$ & 0 & $0.018 \pm 0.00028$ & 0 & 0 \\
\hline Alnus & $1,597 \pm 4.10$ & 100 & $0.285 \pm 0.01560$ & 97 & 99 \\
\hline Low-input pastures & $1,186 \pm 5.81$ & 39 & $0.023 \pm 0.00003$ & 2 & 21 \\
\hline Intense pastures & $1,167 \pm 5.10$ & 36 & $0.026 \pm 0.00040$ & 3 & 20 \\
\hline
\end{tabular}

CMF, catchment modelling framework; ET, evapotranspiration; MF, momentum flux.

${ }^{\star} \mathrm{ET}$ and MF are simulated with the coupled SoBraCo-CMF mode ${ }^{33}$. The model is forced with data of a micrometeorological station ${ }^{33}$. Optical and physiological as well as soil model parameters are derived from field observations presented in Bendix et al. ${ }^{56}$, Silva et al. ${ }^{33}$ and from literature (for more details, refer to Supplementary Table 12 and Table 2 in Silva et al. ${ }^{33}$ ). 
Annual interception is low for pasture but high for abandoned pasture and Pinus. Water returned to the atmosphere through ET dominates the water relations in the tree plantations, while discharge driven by groundwater recharge is the main hydrological component of both active and abandoned pasture. The amount of water infiltrating the soil is offset by plant transpiration, and thus its total share is lower in the tree plantations. The fraction of overland flow is dependent on steepness of slope, level of soil compaction and vegetation cover. Steepness of slope remains constant in the model, but the other two factors are allowed to vary. The results for overland flow range between 2 and $4 \%$ of precipitation, thus representing only a minor fraction.

If a large amount of discharge is desired $\left(P_{\mathrm{k} 1}\right)$, Pinus proves to be the best option, followed by abandoned pasture, Alnus, and the two active pasture options. In the second case $\left(P_{\mathrm{k} 2}\right)$, the ecological index value of the tree plantations increases considerably. Thus, ranking can also depend on location. On steep slopes with soils with high levels of conductivity water retention is more desirable, whereas on flatter ground with compacted soil discharge is more important.

Soil quality is essential in maintaining the long-term productivity, and thus the sustainability, of the provisioning services of our restoration options. The chosen indicators (Table 6 and Supplementary Table 7) are well known to vary in response to land-use change ${ }^{36}$, to support plant productivity ${ }^{37}$ and to contribute to soil biodiversity ${ }^{38}$.

The dominant soil types in the research area are Haplic or Folic Cambisols, and Mollic Cambic Umbrisols ${ }^{36}$. Burning the original forest fertilizes the mineral top soil, raises its $\mathrm{pH}$ and results in soils with higher contents of both organic carbon and total nitrogen, but extremely low phosphate availability ${ }^{39}$. The burnt litter layer slowly regenerates in tree plantations but not on pasture. Regarding the assessment of soil quality, we focus here on sustainable plant productivity ${ }^{40}$ (Table 6).

The soil quality determined for the various land-use options allows for a ranking, although two of the seven indicators-Cand $\mathrm{N}$-mineralization rates-differ only moderately among the alternatives. Still, they are important here and in possible other applications of our assessment approach, as they are associated with different microbial communities ${ }^{40}$. Intense pasturing produces the best soils, with high organic carbon content, high microbial biomass and nitrogen mineralization rates, as well as high phosphate content. The relatively acidic $\mathrm{pH}$ in this variant results from artificial fertilization. The soil on abandoned pasture is inferior, and in its overall quality, similar to that under Alnus and low-input pasture. Afforestation with Pinus decreases the soil quality dramatically due to acidification and the concomitant decline in base saturation, soil organic and microbial carbon content. However, due to the acidic $\mathrm{pH}$, availability of phosphate increases. As Alnus is able to fix nitrogen ${ }^{41}$, which improves most of the soil quality indicators, the soil under Alnus may get better with time.

Socio-economic indicators. Economic investigations of the restoration options are imperative for analysing the likelihood that they will actually be implemented. Thus, we assess benefits from timber or food production based on their simulated market value (household data are given in Supplementary Data 1 and Supplementary Table 8). The analysis of the BAU land-use option (pasturing after forest clearing) provides data for comparison. We use the net present value (NPV, Supplementary Methods) to rank the benefits of each option from an economic perspective.

The NPV (calculated using a 5\% discount rate) of the active land-use alternatives ranges from US\$ 127 (low-input pasture) to US\$ $1,435 \mathrm{ha}^{-1}($ Alnus $)$, which is in accordance with results from

Table 5 | Rating of the key element 'Hydrological regulation' (indicator value \pm s.e.m.)^.

\begin{tabular}{|c|c|c|c|c|c|c|c|}
\hline \multirow[t]{2}{*}{ Land-use option } & \multicolumn{2}{|c|}{ Overland flow } & \multicolumn{3}{|c|}{ Area-specific discharge } & \multirow[t]{2}{*}{$\boldsymbol{P}_{\mathbf{k} 1}$} & \multirow[t]{2}{*}{$\boldsymbol{P}_{\mathbf{k} 2}$} \\
\hline & (mm per year) & $P_{\mathbf{i}}$ & (mm per year) & $\boldsymbol{P}_{\mathbf{i}(+)}$ & $\boldsymbol{P}_{\mathrm{i}(-)}$ & & \\
\hline Abandoned pastures & $75 \pm 3.74$ & 4 & $927 \pm 6.90$ & 100 & 0 & 52 & 2 \\
\hline Alnus & $38 \pm 0.84$ & 81 & $283 \pm 3.95$ & 0 & 100 & 41 & 91 \\
\hline Low-input pastures & $75 \pm 2.81$ & 3 & $677 \pm 6.97$ & 61 & 39 & 32 & 22 \\
\hline Intense pastures & $77 \pm 2.93$ & 0 & $695 \pm 6.11$ & 64 & 36 & 32 & 18 \\
\hline
\end{tabular}

CMF, catchment modelling framework.

${ }^{\star}$ Reported values are based on process-based model simulated data from the coupled CMF-SoBraCo setup adapted to the local land-use option and forced by local climate data (see Table 4).

\begin{tabular}{|c|c|c|c|c|c|c|c|c|}
\hline $\begin{array}{l}\text { Land-use } \\
\text { option }\end{array}$ & $\mathbf{p H}^{\dagger}$ & SOC (\%) & BS (\%) & $\begin{array}{c}\text { MBC } \\
\left(\mathrm{mg} \mathrm{kg}^{-1}\right)\end{array}$ & $\begin{array}{c}\mathrm{C}-\text { min }\left(\mathrm{g} \mathrm{CO}_{2}-\mathrm{C}\right. \\
\text { per } \mathrm{kg} \mathrm{SOC})\end{array}$ & $\begin{array}{l}\mathbf{N}-\min ^{\ddagger} \text { (mg N } \\
\mathbf{k g}^{-1} \text { per day) }\end{array}$ & $\begin{array}{c}\mathrm{PO}_{4}-\mathrm{P} \\
\left(\mathrm{mg} \mathrm{kg}^{-1}\right)\end{array}$ & $\boldsymbol{P}_{\mathbf{k}}$ \\
\hline $\begin{array}{l}\text { Abandoned } \\
\text { pastures }\end{array}$ & $4.5 \pm 0.09(98)$ & $9.5 \pm 0.18(55)$ & $11.5 \pm 2.64(21)$ & $1,088 \pm 51(65)$ & $3.9 \pm 0.18(100)$ & $2.3 \pm 0.27(65)$ & $0.5 \pm 0.09(0)$ & 58 \\
\hline Alnus & $4.3 \pm 0.04(89)$ & $7.9 \pm 0.67(22)$ & $30.4 \pm 1.79(100)$ & $1,065 \pm 80(63)$ & $3.1 \pm 0.13(0)$ & $2.7 \pm 0.49(85)$ & $1.3 \pm 0.22(15)$ & 53 \\
\hline Pinus & $3.6 \pm 0.13(0)$ & $6.8 \pm 0.76(0)$ & $6.4 \pm 1.21(0)$ & $576 \pm 75(0)$ & $3.7 \pm 0.49(75)$ & $1.9 \pm 0.31(45)$ & $5.8 \pm 1.21(96)$ & 31 \\
\hline $\begin{array}{l}\text { Low-input } \\
\text { pastures }\end{array}$ & $4.5 \pm 0.18(100)$ & $10.6 \pm 0.58$ & $16.9 \pm 1.30(44)$ & $1,065 \pm 102(63)$ & $3.5 \pm 0.31(50)$ & $1.0 \pm 0.22(0)$ & $0.6 \pm 0.13(2)$ & 48 \\
\hline $\begin{array}{l}\text { Intense } \\
\text { pastures }\end{array}$ & $4.1 \pm 0.09$ & $11.7 \pm 0.40(100)$ & $11.9 \pm 1.30(23)$ & $1,359 \pm 65(100)$ & $3.2 \pm 0.27$ & $3.0 \pm 1.12(100)$ & $6.0 \pm 1.79(100)$ & 73 \\
\hline
\end{tabular}


Table 7 | Rating of the 'Economic' key elements (indicator value \pm s.e.m.)^.

Land-use option

Abandoned pastures

Alnus

Pinus

Low-input pastures

Intense pastures
Net present value for discount rate:

\begin{tabular}{ccc}
\hline $\mathbf{5 \%}$ (US\$ ha $^{-\mathbf{1}}$ ) & $\boldsymbol{P}_{\mathbf{i}}$ & $\mathbf{8 \%}$ (US\$ ha $^{-\mathbf{1}}$ ) \\
\hline $0 \pm 0$ & 0 & $0 \pm 0$ \\
$1,435 \pm 649$ & 100 & $619 \pm 394$ \\
$1,322 \pm 586$ & 92 & $561 \pm 373$ \\
$127 \pm 146$ & 9 & $-156 \pm 129$ \\
$1,060 \pm 264$ & 74 & $485 \pm 234$
\end{tabular}

*Product (timber, milk and meat) quantities estimated based on tree and grass biomass predictions, and possible number of cattle calculated from simulated grazing rounds plus measured nutrition value of grass; local timber prices and harvesting costs, and prices and costs for milk and meat production contained in Supplementary Data 1; uncertainty from Monte-Carlo simulations, coefficients of variation ${ }^{43}$ from FAO time series data for prices and productivities, as well as from simulated fire risks based on remote sensing data.

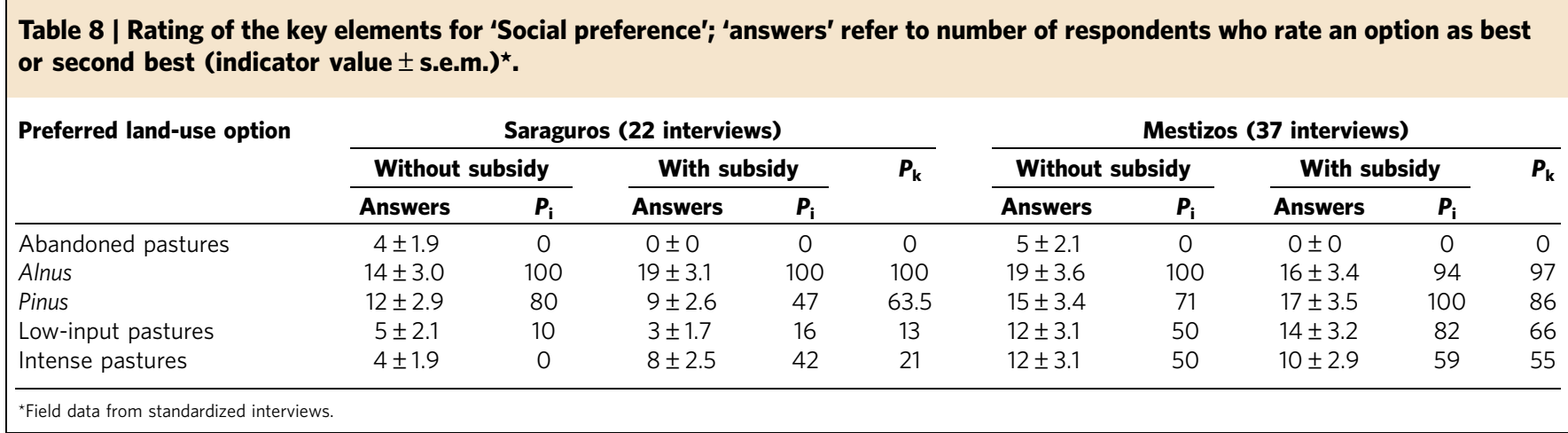

previous studies ${ }^{42}$. Payback periods from 10 (intense pasture) to 18 years (low-input pasturing) are required to recoup initial investment costs (Table 7). Among the pasture options, the intense variant is best in economic terms, with an NPV of US\$ $1,060 \mathrm{ha}^{-1}$. To simulate a greater preference for immediate net revenues with low initial costs, an $8 \%$ discount rate is also tested. In this case, the relative position of leaving land abandoned improves, as the NPVs of the active management alternatives decrease under these conditions. Intense pasture (13 years) and afforestation (16 years), however, still break even within the time span considered.

The land-use variants differ widely in the distribution of net revenues over the 20 -year time period. For both afforestation options, we find only 3 years with positive, albeit high, net revenues (Supplementary Table 9), while the pasture options generate positive net revenues in 18 years. Owing to the concentration of net revenues in only 3 years, the diversification of annual market and production risks in the afforestation options is not comparable to that of the pasture options, for which the 'averaging effect' is much stronger. The uncertainty of the intense pasture's NPV is thus only around $50 \%$ of that of the tree plantations.

From a farmer's perspective, all restoration options must be compared with the BAU option of land use in the study region ${ }^{43}$ (explained in Supplementary Methods). All restoration options tested are less favourable from an economic point of view than BAU, for which the NPV (US\$ 1,435 and $1,765 \mathrm{ha}^{-1}$ at $8 \%$ and $5 \%$ discount rates) is always higher than that of the best restoration option. The annualized differences between the NPVs (8\% discount rate) of BAU and the restoration scenarios are US\$ $87 \pm 52 \mathrm{ha}^{-1}$ per year (Alnus as reference) or US\$ $100 \pm 40 \mathrm{ha}^{-1}$ per year (intense pasture as reference). These amounts suggest the order of magnitude of the financial transfers that might be required to convince farmers to establish one or more restoration options.
Social preference in the context of this method represents information beyond that contained in the economic indicators. In addition to the tangible values reported above, people tend to implicitly include intangible cultural values when expressing their preference for land-use options. Thus, the success of recommendations regarding land use depends largely on this indicator, as farmers must evaluate whether a particular option fits not only into their overall economic, but also into their household and socio-cultural situations ${ }^{44}$.

Using standardized questionnaires (Supplementary Methods), we asked Mestizo and Saraguro farmers about their preferences and find an inclination towards afforestation (Table 8 and Supplementary Table 10). Farmers of both ethnic groups list 'lack of timber' and 'shortage of labour' as the main reasons for this preference. Without the benefit of subsidies, farmers of both ethnic groups prefer Alnus over Pinus; however, given the possibility of external subsidies, the Mestizos show a slight preference for Pinus. With respect to repasturization, low-input pasture appears to be more attractive than the intense option. Concerns about adverse ecological effects and the costs for fertilizer are the main reasons given by Mestizos for preferring low-input pasturing: more than one fourth of Mestizos interviewed (10 out of 37 ) believe that agrochemicals damage or 'sterilize' the soil. The Saraguros, however, state a higher preference for intense pasture if subsidies are available, but nevertheless consider reforestation with Alnus to be the best option.

The interviews show a clear preference for tree plantations. Interestingly, leaving areas abandoned is not favoured at all. Farmers express willingness to re-utilize abandoned areas but are less ready to invest high upfront costs or substantial labour to do so. Differences in the acceptance level even among different ethnic groups support the necessity and usefulness of this indicator, especially when applied in other regions. 


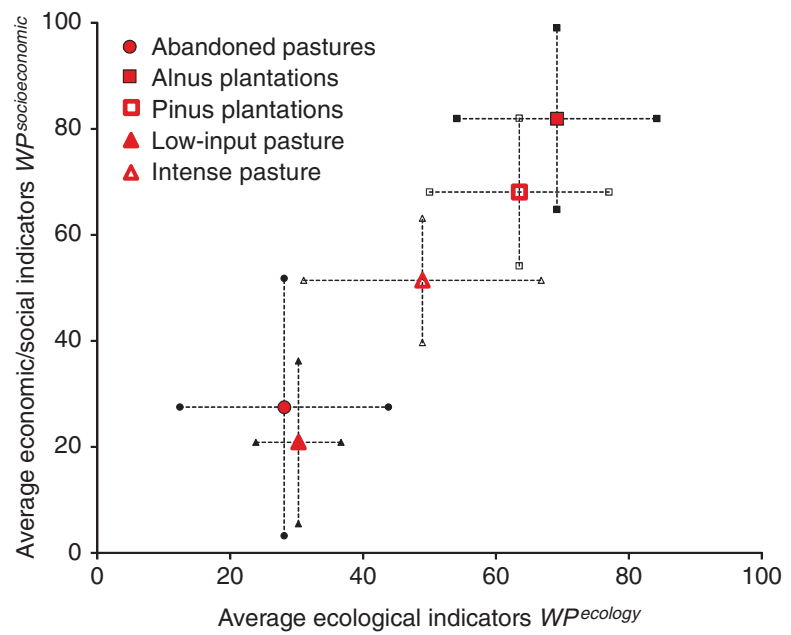

Figure 1 | Ecological versus socio-economic index values. Average of key element $-P_{k}$-indices of the five investigated options of land use if water retention is considered positive. Error bars (whiskers) indicate \pm s.e.m., coefficient of correlation is $\rho=0.99\left(t_{\rho}=11.77 ; p_{t}<0.001\right)$; the statistic of a Kruskal-Wallis one-way analysis of variance is $H=13.4\left(p_{H}<0.01\right)$ for differences between overall average index values ( $n=8$ key elements for each land-use option). A priori hypotheses about differences between single land-use options or groups of land-use options are tested as statistical contrasts using rank transformed data with: $\mathrm{Ab}$, abandoned pastures; $\mathrm{A}$, Alnus; P, Pinus; L, low-input pastures; I, intense pastures. Contrast 1 , associated with the hypothesis $(A+P+L+I) / 4>A b$, tests if restoration options on average improve ecological and socio-economic values, and results in a significant $t_{\mathrm{c} 1}=2.3\left(p_{\mathrm{c} 1}<0.025\right)$. Contrast 2 , associated with the hypothesis $(A+P) / 2>(I+L) / 2$, tests if afforestations perform better than pasture, and results in a significant $t_{\mathrm{c} 2}=3.1\left(p_{\mathrm{c} 2}<0.025\right)$. Contrast 3 focuses on the hypothesis $\mathrm{A}>\mathrm{P}$ and tests if Alnus outperforms Pinus, and results in a nonsignificant $t_{\mathrm{c} 3}=0.9$. Contrast 4 , associated with the hypothesis $I>L$, tests if intense pastures perform better than low-input pastures, and results in a weakly significant $t_{\mathrm{c} 4}=1.6\left(p_{\mathrm{c} 4}<0.100\right)$ (Supplementary Table 22).

Synopsis and sensitivity of indices. To gain more insight into the possible trade-offs between ecological and socio-economic ecosystem indices, and to support science-based decision making, we analyse the correlation between the average ecological and socioeconomic key elements (Fig. 1).

Spanning considerable ranges, the ecological and socioeconomic indicators are strongly positively correlated and show a low degree of trade-off -+0.99 with high water retention, and +0.94 with high discharge considered most desirable. Leaving areas abandoned and low-input pasture both appear less efficient than the other options. Ranking by the ecological indices alone places afforestation on top, irrespective of the hydrological key element used (Fig. 2a).

Alnus plantations rank slightly higher than Pinus plantations, followed by intense pasture. Afforestation and intense pasture both rank higher than the original state of 'abandoned pasture'. Low-input pasture is ecologically equal to abandoned pasture when water retention is assessed as positive, but falls short when water discharge is more desirable.

The economic results (Fig. 2b) are supported by the analysis of the preferences obtained from the household survey, which show an affinity for afforestation among all respondents.

Sensitivity analysis (Supplementary Tables 11-21) shows our ranking to be sufficiently robust in this context and provide an indication of how this ranking might be affected by subjective weighting of key elements (Supplementary Fig. 2). The ranking
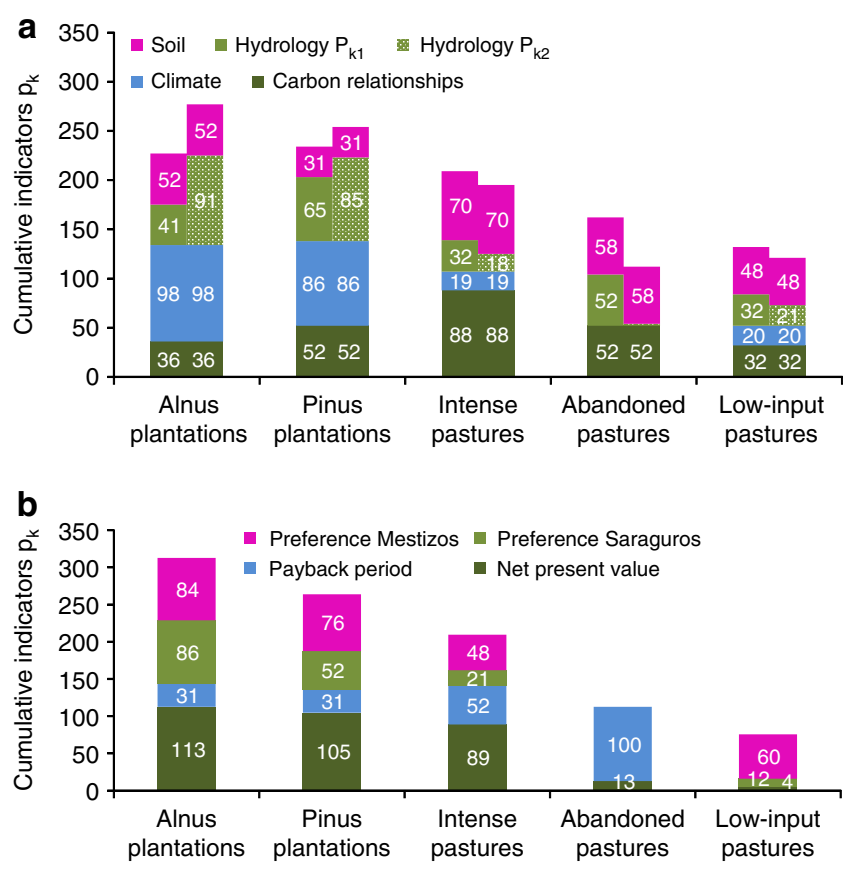

Figure 2 | Accumulated index values. (a) Summed index values on ecological indicators are shown for the five land-use options with $P_{\mathrm{k}}$ : discharge considered positive (left columns) and $P_{k 2}$ : water retention preferred (right columns). (b) Summed index values on socio-economic indicators for the five land-use options are depicted. Preferences distinguish between indigenous Saraguro and Mestizo settlers. With payback periods, we measure how long settlers will need to receive their money invested back and the NPV is the sum of all appropriately discounted net revenues.

remains the same when we account for the size of the differences by applying equation (3) (see Methods) in an attempt to prevent overestimation of small differences (Supplementary Fig. 2a). However, with this type of weighting, the ecological indicators distinguish less clearly among the restoration options. Although some ecological differences may be considered small (for example in $\mathrm{N}$-mineralization), their importance may be high. Such differences are scaled appropriately with our approach. Another advantage is its relatively high immunity against uncertainty. By calculating the relative position of the indicator values in the range between their maximum and minimum, we obtain robust rankings that are largely unaffected by indicator uncertainty (see below). When using the $95 \%$ confidence limits to represent pessimistic and optimistic indicator estimates and account for uncertainties (according to equation (4) in Methods), some landuse options change their rank position, but only for single indicators. One example of this is the option pair Alnus and intense pasture, which trade positions between ranks 1 and 3 for the indicator NPV (8\%) depending on whether the analysis is based on optimistic or pessimistic assumptions (Supplementary Table 20). However, where process-based model results contribute to the assessment, the individual $\left(P_{\mathrm{j}}\right)$ and integrated $\left(P_{\mathrm{k}}\right)$ indicator assessment scheme are very robust (Supplementary Tables 15-18). In sum, we do not see any significant overall variation in the average normalized indicators (Supplementary Fig. 2b,c). Only under pessimistic assumptions does the correlation between socio-economic and ecological indicators, and significance levels weaken (Supplementary Fig. 2c and Supplementary Table 22). Given the generally high level of robustness of our ranking system, we conclude that both our normalization procedure and assessment approach are reliable. 


\section{Discussion}

Assessing the potential for the provision of ecosystem functions and benefits from various restoration options using normalized ecological and socio-economic indicators is a novel approach in science-directed decision support. It is clear that any such assessment is context specific and dependent on the particular objectives of the decision makers in a given ecological and socioeconomic context. Nevertheless, our study shows that the often ignored socio-economic indicators are essential components of a comprehensive assessment approach to guide the way to a possible implementation of desirable land-use options. Their extremely strong correlation with ecological indicators does, however, not necessarily mean that a cause-response relationship exists. It rather indicates that trade-offs between average indicators are low. Thus, to avoid assessing the consequences of restoration options overly optimistic, it is important to quantify the short-term socioeconomic trade-offs when compared with BAU. Given this premises and combined with a thorough analysis of uncertainties, both the indicator system and the normalization procedure developed in our study are useful for comprehensive evaluations of ecosystem functions and benefits in other study regions.

The choice and quality of indicators are crucial issues. For example, our quantitative hydrological indicators showed realistic results when compared with other studies ${ }^{45,46}$. However, water quality could also be an important indicator ${ }^{25}$, as intense pasture requires the use of herbicides and inorganic fertilizer, some of which could end up in rivers and groundwater. This problem can be mitigated by proper handling, that is, application of any agrochemical only under suitable weather conditions. As overland flow is generally low ( $2-4 \%$ of precipitation), the volume of water for direct downhill transport of the chemicals is also small, reducing the risk of displacement. In fact, our observations of the control plots located down slope from herbicide-treated plots did not show any herbicide effect. Carryover effects of any of the herbicides applied via the soil to the subsequent pasture were also not observed ${ }^{24}$. A similar consideration applies to fertilizer treatment, as the poor soils act as strong nutrient sinks. Nevertheless, some leaching of nitrate cannot be completely ruled out, although we did not observe a statistically significant fertilization effect in reference plots situated down slope.

In contrast to other authors ${ }^{28}$, we did not use biodiversity as an indicator in our study, as it is very low in the options investigated and-even on long-abandoned pasture-is not at all comparable to that of the pristine forest. Stable shrubby vegetation made up of bracken and several prolific roadside species formed a closed canopy ${ }^{21}$, which can persist for decades (Supplementary Methods). Species richness of selected other groups of organisms such as birds and moths is also low compared with that found in pristine forests. Thus, the anthropogenic landscapes flanking forests are merely sinks for such species, mainly due to a shortage of food resources, nesting sites and other ecological factors necessary to provide suitable habitats. Consequently, the land-use options considered here represent 'novel ecosystems' that are expected to persist, rather than merely being an interim stage in the process of returning to a near-natural forest ${ }^{47-49}$. Natural grassland suitable for use as pasture does not occur in the research area and thus introduced grass species (Setaria sphacelata and Melinis minutiflora) are used. Some accompanying herbs, grasses and shrubs are indigenous, but most are cosmopolitans ${ }^{50}$, resulting in limited phytodiversity. Every hectare of natural vegetation-dense forest up to $2,800 \mathrm{~m}$ asl and shrub páramo above the tree line $\mathrm{e}^{51}$-that is not cleared for production of short-lived pastures preserves much more of the biological diversity than pasture, afforested areas or abandoned lands can maintain.
Still, some barriers must be overcome to implement the advantageous restoration options, as all of them impose shortterm economic trade-offs. The quantified trade-off of US\$ 87 in opportunity costs resulting from afforestation with Alnus, or the US\$ $100 \mathrm{ha}^{-1}$ per year costs incurred when intense pasture is implemented are, however, subject to a high level of uncertainty. If we use the upper $95 \%$ confidence limit of the estimated costs to include the possible compensation amounts demanded with a 0.975 probability, we end up with approximately US\$ $180 \mathrm{ha}^{-1}$ per year to be transferred to farmers. Spending this money could be worthwhile, given the amount of $\mathrm{CO}_{2}$ emissions ${ }^{42}$ and losses of biodiversity, which could be avoided, and the other ecological benefits, which could be achieved if farmers were to re-utilize their abandoned lands rather than clearing natural forest. In our study area, the preservation of natural forests may prevent the emission of $272 \mathrm{Mg} \mathrm{CO}_{2}$ per hectare ${ }^{43}$. Consequently, a moderate price for $\mathrm{CO}_{2}$ emission allowances of US\$ 7.5 per Mg would result in a NPV of US\$2,040 ha ${ }^{-1}$, which is equivalent to an annualized payment of US\$ 208 over a 20 -year period (based on an $8 \%$ discount rate). Carbon markets could, thus, possibly cover the compensation amounts needed to convince famers to choose restoration options.

However, to improve conservation efficiency, transfers to landowners as rewards for conserving their forests-for example, under the REDD + mechanism ${ }^{52}$ or other national programmes such as the Ecuadorian 'Socio Bosque'53 — should be made conditional on the implementation of restoration activities on abandoned land, considering also agricultural options in the future $^{54}$. In regions with chaotic property rights regimes, as in our study area ${ }^{44}$, the implementation of the restoration options could also be supported by offering property rights contracts (possibly coupled with additional financial compensation). The size of the abandoned area, its accessibility and distance to the farm must also be considered in recommendations, as the advantages of afforestation increase with distance to farm, whereas those of intense pasture increase with increasing accessibility.

As a general conclusion, it appears important for farmers to receive appropriate education and financial support to highlight and strengthen the link between more long-term economic thinking and ecological considerations. Our study shows that preference analyses are crucial parts of studies on ecosystem functions and benefits. The preference expressed by the majority of subsistence farmers for restoring abandoned pasture areas through afforestation demonstrates that implementation of this option is realistic. Farmers could benefit from more moderate upfront costs, the lack of a need for further inputs of labour until thinning and harvest activities take place and flexibility with respect to the timber market, which ultimately results in a reduction in risk ${ }^{54}$. Pinus could be used as a nurse-tree species to facilitate regeneration of useful native trees. Restoration of abandoned pasture for intensive re-use may be more attractive on medium to large farms (50-100 ha), which are already integrated into agricultural markets and can afford higher upfront investments. The implementation of intense pasturing will require a higher level of input from consulting experts. Similar conclusions will be valid for other tropical mountain regions, from $1,500 \mathrm{~m}$ altitude up to the tree line.

As evidenced by the short-term economic trade-offs inherent to each of the restoration options, a farmer's decision to afforest, re-cultivate pasture or leave areas abandoned depends-in addition to available labour capacity-on the availability of affordable financial support from government programmes or credit institutions. Studies such as ours can help raise awareness about possibilities for recultivating abandoned land, thus enhancing the effectiveness of incentive programmes, which could ultimately relieve pressure on natural ecosystems ${ }^{42}$. 


\section{Methods}

Land-use options and period considered. We investigate two variants each of afforestation and pasture restoration as feasible options with respect to their ecological value, their economic benefits and the preferences for each option among both Mestizo and indigenous Saraguro farmers. A former pasture area that has been abandoned for 14 years is our reference. We consider a 20 -year period to be a meaningful time span for the study, as it represents the common rotation time for tree plantations in the region.

Data. The present work synthesizes the findings of a multi-disciplinary research initiative that started ecosystem studies in southern Ecuador in 1998. Since then, a solid knowledge base has accumulated with data that is used in this study. Models parameterized with field data are used to obtain the results for some indicators over the 20 -year period during which we assume nearly constant environmental conditions. Other indicators were either measured directly in the field or obtained from interviews. Field data for carbon relationships and soil quality has been obtained from previous peer-reviewed work carried out by members of the multidisciplinary research team $24,30,31,36,40,55-57$. Model-based indicators have been estimated with models published in peer-reviewed journals, which have been developed for or adapted to the study region. Model estimates include

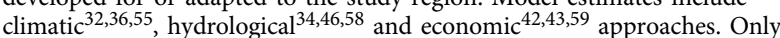
occasionally have models from other literature been used to complement our data ${ }^{60,61}$. The results of the interviews (Supplementary Table 10) to obtain data on the social preferences have not been published in peer-reviewed journals before. Details, as well as an assessment of the methods are presented in Supplementary Methods.

Research area. The research area ${ }^{62}$ is located in the eastern range of the tropical Andes of southern Ecuador $\left(3^{\circ} 58^{\prime} 30^{\prime \prime} \mathrm{S}\right.$ and $\left.79^{\circ} 4^{\prime} 25^{\prime \prime} \mathrm{W}\right)$. Our experimental sites were established on areas with a $35^{\circ}$ slope located between 1,800 and $2,100 \mathrm{~m}$ asl, and covering a total area of abandoned pasture of 150 ha. Analysis of aerial photographs shows that forest clearing has been occurring since the 1960s, and pasture farming has been done for about the last 35 years. Because of heavy infestation by weeds-mostly bracken fern-many pastures were abandoned about 15 years ago.

Normalization of indicators and statistical analyses. Unitary performance indices are calculated for each indicator $\left(P_{\mathrm{i}}\right)$ and for each of the key elements $\left(P_{\mathrm{k}}\right)$. $P_{\mathrm{i}}$ (equation (1)) reflects the relative position of a land-use option in the achievable range. $R_{\mathrm{i}}$ is the indicator value, $\mathrm{i}$ the land-use option, $R_{\min }$ the least desirable and $R_{\max }$ is the most desirable value for the indicator.

$$
P_{\mathrm{i}}=\frac{R_{\mathrm{i}}-R_{\min }}{R_{\max }-R_{\min }} \cdot 100
$$

As equation (1) might result in inflation of small differences through its normalization approach, we impose an objective weighting factor, $w_{\mathrm{d}}$, proportional to the maximum achievable difference to test the robustness of our $P_{\mathrm{i}}$. Specifically, we use the total range of variation divided by the indicator's maximum as the weight, $w_{\mathrm{d}}$, to account for the relative size of the maximum achievable difference and to see how our results change through this type of weighting (equation (2)).

$$
P_{\mathrm{i}}=\frac{R_{\mathrm{i}}-R_{\min }}{R_{\max }-R_{\min }} \cdot w_{\mathrm{d}} \cdot 100 \quad \text { with : } \quad w_{\mathrm{d}}=\frac{R_{\max }-R_{\min }}{R_{\max }}
$$

Adjusted according to equation (2), equation (1) then simplifies to equation (3):

$$
P_{\mathrm{i}}=\frac{R_{\mathrm{i}}-R_{\min }}{R_{\max }} \cdot 100
$$

Although equation (3) constitutes a weighting of the normalized indicators, we also conduct sensitivity studies in which we test scenarios using either pessimistic or optimistic estimates for our indicators to identify possible impacts of uncertainty. To obtain the pessimistic and optimistic estimates, 95\% confidence limits for the estimated indicators are used. The interpretation of a confidence limit as pessimistic or optimistic depends on what is desirable. If a high indicator value is desired (for example NPV), the lower confidence limit is considered to be the pessimistic (near worst-case) estimate. If instead a low indicator value is preferable (for example, payback period), the upper confidence limit is considered pessimistic (equation (4))

$$
\begin{gathered}
R_{\mathrm{i}, \text { opt,pess }}=R_{\mathrm{i}} \pm t_{\alpha=1-0.95, d f} \cdot S E M_{\mathrm{i}} \\
S E M_{\mathrm{i}}^{\text {Sample }}=\frac{S D_{\mathrm{i}}}{\sqrt{n}} \\
S E M_{\mathrm{i}}^{\text {Sample_Interviews }}=n \cdot \sqrt{p_{\mathrm{i}} \cdot\left(1-p_{\mathrm{i}}\right) / n} \\
S E M_{\mathrm{i}}^{\text {Monte_Carlo }}=S D_{\mathrm{i}}^{\text {Simulated_Mean }}
\end{gathered}
$$

Here, $S E M_{\mathrm{i}}$ is the uncertainty associated with the estimated mean indicator value for restoration option i, commonly understood as the s.d. of the mean and $t_{\alpha=1-0.95, d f}$ is a number obtained from a Student's $t$-distribution, which is used to form a $95 \%$ confidence limit depending on the degrees of freedom, $d f$. For indicator values derived from sampling, we obtain $S E M_{\mathrm{i}}$ by dividing $S D_{\mathrm{i}}$ (the s.d. among individual samples) by the square root of $n$ (number of samples) (equation 5). For

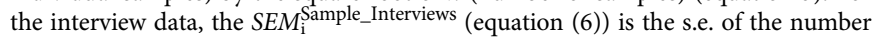
of answers where a restoration option is chosen as the best or second best alternative. Here, $n$ is the sum of all responses of 'best' or 'second best', and $p$ is the relative frequency of the responses 'best' and 'second best' for that restoration option. In detail, $p$ is the number of 'bests' and 'second bests' for option $i$ divided by $n$-the sum of all answers for a given indicator naming these categories. For the model estimates, $S E M_{\mathrm{i}}^{\text {Monte_Carlo }}$ is computed directly as the standard deviation, $S D_{\mathrm{i}}^{\text {Simulated_Mean }}$, of the mean values derived from the simulated repetitions (equation 7). Finally, normalization of either $R_{\mathrm{opt}}$ or $R_{\text {pess }}$ is carried out according to equation (1)

$P_{\mathrm{k}}$ (equation 8) is the average of all (weighted or not weighted) $P_{\mathrm{i}}$ values, which contribute to a particular key element ( $n_{\mathrm{i}}$ is the respective number of indicators).

$$
P_{k}=\frac{1}{n_{\mathrm{i}}} \sum_{\mathrm{i}} P_{\mathrm{i}}
$$

The ecological and socio-economic average of index values for each of the landuse options are determined by average performance indices (equation 9) (weighted or not weighted), where $o$ is the land-use option, $c$ the category, $n_{\mathrm{k}}$ is the number of key elements and $w_{\text {sub }}$ is a subjective weighting factor.

$$
W P_{o}^{c}=\frac{1}{n_{\mathrm{k}}} \sum_{\mathrm{k}} w_{\mathrm{sub}} \cdot P_{\mathrm{k}}
$$

$w_{\text {sub }}$ is set equal to 1 for standard analyses. For specific scenarios, however, we test subjective weighting factors to favour preferred key elements.

We compute Pearson correlations between ecological and socio-economic indicators for $P_{\mathrm{k}}$ values and associated $t$ - and $p$-values (Fig. 1 and Supplementary Fig. 2). Given our-through normalization-truncated distributions of $P_{\mathrm{i}}$ index values, non-parametric Kruskal-Wallis analyses of variance served to test the impact of land-use options on the average $P_{\mathrm{k}}$ ( $n_{\mathrm{k}}=8$ for each option). Associated with a one-way analysis of variance for rank-transformed data, contrasts based on a priori formulated hypotheses are computed finally to distinguish between the land-use options investigated (Supplementary Table 22).

Biomass production and carbon content. On the abandoned areas (control plots), above-ground plant biomass (bracken leaves) was harvested individually from four $25-\mathrm{m}^{2}$ plots and dried for further analysis, while below-ground biomass was estimated from roots and rhizomes extracted from soil cores $(40 \mathrm{~cm}$ deep, $6 \mathrm{~cm}$ diameter, $n=3$ per plot). Aliquots of the dried plant material were analysed in a CNS-Analyser (vario EL III/elementar, Heraeus). Production of above-ground biomass was determined based on the amount of standing biomass and the life span of the bracken leaves ${ }^{30}$. Below-ground biomass production was estimated using the SoBraCo-model ${ }^{33}$. On the pastures, biomass production and total biomass were determined using $4 \times 4 \mathrm{~m}$ plots with four repetitions per option during the second year of pasture management after complete removal of the harvest from the first year. Grazing was simulated by cutting the grasses and leaving a basal layer of $20 \mathrm{~cm}$. At the end of the year, the grass was completely harvested. For calculation of the standing crop, see Supplementary Methods. Below-ground biomass was determined and root biomass production was estimated as described above, with cores taken below, near and between grass tufts. SEM was calculated according to equation (5). Based on data from the experimental plots as described in Günter et al. ${ }^{63}$, growth of the Pinus and Alnus trees over 20 years was calculated. This was done using regression curves to correlate dbh (diameter at breast height) and height with the independent variables age and tree density. Tree density is based on an initial density of 1,111 trees per hectare and an observed annual mortality rate of $2 \%$. To establish the regression curves, Pinus was recorded on two sites with 16 plots each (32 plots of $10.8 \times 10.8 \mathrm{~m}$, all 6 years old) and on one site with two circular plots (radius $20 \mathrm{~m}$, $1,256 \mathrm{~m}^{2}, 25$ years old). Data for Alnus was measured on two sites, one with 14 and the other with 16 plots ( 30 plots $10.8 \times 10.8 \mathrm{~m}, 7$ years old) and one site with 10 plots (size on average $777 \mathrm{~m}^{2}, 8$ years old). Above-ground biomass and carbon content are estimated using both allometric equations and information adopted from the literature (Supplementary Methods). Uncertainty is modelled by means of Monte-Carlo (MC) simulation (3,000 repetitions for each afforestation option), where the coefficients of regression models are considered random. Regression coefficients as means, and their uncertainties, in the form of their s.e. allow us to draw randomly fluctuating coefficients for each simulation run to predict forest growth. The calculation of SEM refers to equation (7).

Climate. The Soil-Vegetation-Atmosphere Transfer model and the vegetation growth model SoBraCo ${ }^{33}$ are used to assess changes in the climate regulation function of the land-use options. SoBraCo is a derivative of the properly validated community land model (CLM, see Lawrence et al. ${ }^{64}$ and Bonan et al. ${ }^{65}$ ). The main difference between SoBraCo and CLM is that in SoBraCo, the calculations used in CLM for some atmospheric variables are replaced by direct forcing with observational data from a specifically designed micro-meteorological station for an average reference year (2008; refer to Supplementary Methods). Hourly environmental forcing data for the 20 -year modelling period is generated using the reference period for the forcing variables (solar irradiation, air temperature, relative 
humidity, wind speed, rainfall, soil water content and soil temperature) and continually re-applying the annual data set over the entire period. Required plantspecific model parameters are derived from measurements at both leaf and root levels at the study site and from data available from the literature (for more details, refer to Supplementary Methods and Supplementary Table 12). CMF is directly coupled with the SoBraCo-model using a Python interface ${ }^{58}$.

Time series of leaf area indices (LAIs) and vegetation height used for parameter forcing for the coupled model over the 20-year period are calculated using field measurements (Supplementary Fig. 1). For Pinus, LAI is estimated based on $\mathrm{dbh}^{60}$. For Alnus, observed leaf numbers from experimental plots and mean leaf area ${ }^{61}$ are used to estimate the mean allometric leaf area $\left(L A_{\text {allom }}\right)$ per tree, as $L A_{\text {allom }}=\operatorname{EXP}(-0.22+1.297 \times \ln (\mathrm{dbh})) . L A_{\text {allom }}$ and the actual number of trees is used to scale LAI up to the plantation level. LAI for grass and bracken are directly derived from LAI field measurements ${ }^{56}$. Uncertainty analysis (for climate and hydrology) of the coupled SoBraCo-CMF model framework is conducted for forcing variable and parameter uncertainties of climate and hydrological indicators, the latter with the help of more than 3,000 MC simulation runs and subsequent calculation of the SEM using equation (7). Based on sensitivity studies and a literature survey, eight (SoBraCo) + two (CMF) model parameters shown to have the biggest influence on model output are chosen (see Supplementary Methods). Most parameters and the form of their probability density functions are based on field observations (for parameters and sources, see Supplementary Tables 12 and 13). The robustness of the integral rating scheme $\left(P_{\mathrm{k}}\right)$ regarding climate and hydrological indicators is tested by comparing the range of the $P_{\mathrm{i}}$ grading considering forcing variable uncertainty (Supplementary Tables 17 and 18). A scenario using $95 \%$ limits for the indicator values (following from equation (4)) derived from the MC analysis (parameter uncertainty) has also been tested (Supplementary Tables 15 and 16).

Hydrology. The $\mathrm{CMF}^{34}$ is used to simulate hydrological processes in a onedimensional soil column and to quantify water fluxes. This model effectively meets the challenges and provides the opportunities called for in hydrological models to support decision making outlined by Guswa et al. ${ }^{66}$ Similar to the finite volume method used by Qu and Duffy ${ }^{67}$, CMF discretises the soil column into soil layers serving as water storages. We use the Richards equation to simulate water flux between cells. Eight soil layers of increasing thickness from the top downwards, each with unique hydraulic properties, are summed to reach a total column depth of $1 \mathrm{~m}$. Water leaving the soil column is routed to the ground water using a Dirichlet boundary condition with a constant negative pressure. An average slope similar to the slope occurring at the site is used. The CMF water balance is as follows: $\Delta$ storage $=$ rainfall $-\mathrm{ET}-$ overland flow - ground water seepage. Groundwater seepage plus overland flow is summed to derive the area-specific discharge. Saturated hydraulic conductivity $\left(k_{\text {sat }}\right)$ for the scenarios is adapted in accordance with local measurements for pasture and forested sites presented by Huwe et al. ${ }^{57}$ To account for the highly conductive litter layer and roots that create additional pore space, the $k_{\text {sat }}$ values of the three top soil layers are increased. ET and throughfall are calculated using the SoBraCo-model ${ }^{33}$, which shows realistic results. For example, the rate of throughfall forwarded to the hydrological model by the plant growth model SoBraCo is well within the range found in other studies in adjacent tropical mountainous rainforest sites ${ }^{45}$ (between $88 \%$ and $97 \%$ of precipitation). Saturated soil depth is set to $-2 \mathrm{~m}$ below soil surface to initialize the model and provide uniform initial conditions. To emphasize the impact of vegetation type, uniform parameters for soil are used for all of the land-use options (Supplementary Methods). Overland flow is simulated as saturation excess. For the analysis of uncertainty, refer to the key element 'Climate'.

Soils. The quantification of our ecosystem function is based solely on empirical data measured on five plots in 2011. Soil samples were taken with an auger (diameter: $6 \mathrm{~cm}$ ). A pooled soil sample of six replicates per plot was analysed for the $0-5$ and $5-10 \mathrm{~cm}$ depth intervals. Soil organic carbon and total nitrogen $(\mathrm{N})$ were quantified using a CNS-Analyzer (vario EL III/elementar, Heraeus). Fresh samples were used for all other measurements, but the data were calculated for dry weight $\left(105^{\circ} \mathrm{C}\right)$. Plant available $\mathrm{PO}_{4}-\mathrm{P}$ was determined by the Bray-P method ${ }^{68}$ and the chloroform-fumigation extraction method was used ${ }^{69}$ for microbial carbon. Gross $\mathrm{N}$ mineralization was measured by the ${ }^{15} \mathrm{~N}$-isotope pool dilution method and soil organic carbon mineralization by $\mathrm{CO}_{2}$ evolution during 14 days of incubation ${ }^{70}$. Soil pH was determined in deionized water. Soil data were gathered for restored pasture beginning 2 years after re-establishment and for tree plantations in the oldest existing plots. Calculation of SEM refers to equation (5).

Economics. The modelled (afforestation) or measured (pasture) biomass production in the form of either timber volume (afforestation) or fodder for a specific number of cattle (pasture) forms the ecological data to be evaluated using local prices and costs. Local historical timber prices and harvesting expenses, reported in Supplementary Data 1, were applied to the afforestation areas to estimate the net revenues from timber production (see Supplementary Table 4 for biophysical timber production and 18 for financial household data). For pasture, extrapolation of simulated grazing generates expected fodder yield, and the number of cattle that can be fed is computed based on the measured nutrient value of the grass. Milk and meat yield, as well as corresponding prices and costs are given in Supplementary
Data 1. The distribution of net revenues over the 20-year time period forms the basis for economic valuation (Supplementary Table 9). The sum of all discounted net revenues (NPV) is used to evaluate the economic returns from the various land-use options and discounting based on discount rates of 5 or $8 \%$. Payback periods are calculated based on discounted net revenues (Supplementary Methods) For the scenario 'pasturing after forest clearing' (BAU), upfront net returns from forest clearing and pasture establishment were obtained from Knoke et al. ${ }^{43}$ and combined with subsequent net revenues from low-input pasture management (Supplementary Table 9). Uncertainty is modelled by means of MC simulation (3,000 repetitions for each restoration option) for the annual net revenues used to calculate NPV and payback periods. Here, net revenues are drawn as random variables for every single year of the 20-year period considered from a normal distribution with the previously estimated expected net revenue as the mean and the s.d. indicated in Supplementary Table 9. After completing the annual simulation of net revenues over the entire 20-year period, a random NPV and payback period are computed for all iterations and SEM is calculated according to equation (7). Year-to-year correlation is set to zero. This appears reasonable, because average year-to-year correlation of revenues (average price obtained times quantity produced) for 10 South American countries was $0.04 \pm 0.21$ according to a data set used by Knoke et al. ${ }^{59}$ Uncertainty coefficients for the land-use options in the study area are derived from coefficients of variation published in an earlier analysis ${ }^{43}$ in our study area. The coefficients of variation reflect compounded s.d. of prices and productivities from Food and Agriculture Organization of United Nations time series data, as well as s.d. caused by failure due to fire (coefficients in Supplementary Table 9).

Social assessment. The preferences of Saraguro and Mestizo farmers for the five proposed land-use options were determined using a standardized questionnaire (Supplementary Methods). This includes questions regarding the land-use preferences of the farmers and their arguments for preferring particular land-use options, as well as information about household composition, ownership of abandoned land and reasons for its abandonment. Two scenarios are tested-one in which farmers reclaim the abandoned areas using their own means (without subsidies) and a second in which farmers receive financial support for major inputs from external agencies (with subsidies).

\section{References}

1. García-Barrios, L. et al. Neotropical forest conservation, agricultural intensification, and rural out-migration: The Mexican experience. BioScience 59, 863-873 (2009).

2. Lambin, E. F. \& Meyfroidt, P. Global land use change, economic globalization, and the looming land scarcity. Proc. Natl Acad. Sci. USA 106, 3465-3472 (2011).

3. Field, C. B., Campbell, J. E. \& Lobell, D. B. Biomass energy: the scale of the potential resource. Trends Ecol. Evol. 23, 65-72 (2007).

4. Tscharntke, T. et al. Global food security, biodiversity conservation and the future of agricultural intensification. Biol. Conserv. 151, 53-59 (2012).

5. Aronson, J. et al. Are socioeconomic benefits of restoration adequately quantified? a meta-analysis of recent papers (2000-2008) in restoration ecology and 12 other scientific journals. Restor. Ecol. 18, 143-154 (2010).

6. DeFries, R. \& Rosenzweig, C. Toward a whole-landscape approach for sustainable land use in the tropics. Proc. Natl Acad. Sci. USA 107, 19627-19632 (2010).

7. Silver, W. L., Kueppers, L. M., Lugo, A. E., Ostertag, R. \& Matzek, V. Carbon sequestration and plant community dynamics following reforestation of tropical pasture. Ecol. Appl. 14, 1115-1127 (2004).

8. Larsson, S. \& Nilsson, C. A remote sensing methodology to assess the costs of preparing abandoned farmland for energy crop cultivation in northern Sweden. Biomass Bioenerg. 28, 1-6 (2005).

9. Aronson, J. \& Alexander, S. Ecosystem restoration is now a global priority: Time to roll up our sleeves. Restor. Ecol. 21, 293-296 (2013).

10. Seppelt, R., Dormann, C. F., Eppink, F. V., Lautenbach, S. \& Schmidt, S. A quantitative review of ecosystem service studies: approaches, shortcomings and the road ahead. J. Appl. Ecol. 48, 630-636 (2011).

11. Boyd, J. \& Banzhaf, S. What are ecosystem services? The need for standardized environmental units. Ecol. Econ. 63, 616-626 (2007).

12. Groot, R. S., de, Wilson, M. A. \& Boumans, R. M. J. A typology for the classification, description and valuation of ecosystem functions, goods and services. Ecol. Econ. 41, 393-408 (2002).

13. Aguirre, N., Palomeque, C., Weber, M., Stimm, B. \& Günter, S. in Silviculture in the Tropics (eds Günter, S., Weber, M., Stimm, B. \& Mosandl, R.) 513-526 (Springer, 2011).

14. Göttlicher et al. Landcover classification in the Andes of southern Ecuador using Landsat ETM + data as a basis for SVAT modelling. Int. J. Remote Sens. 30, 1867-1886 (2009).

15. Ellenberg, H. Man's influence on tropical mountain ecosystems in South America. J. Ecol. 67, 401-416 (1979).

16. Lauer, W. Human development and environment in the Andes: a geoecological overview. Mt. Res. Dev. 13, 157-166 (1993). 
17. Sarmiento, F. O. Arrested succession in pastures hinders regeneration of Tropandean forests and shreds mountain landscapes. Environ. Conserv. 1, 14-23 (1997).

18. Ruddle, K. Problems of resource use in humid tropical high mountains. Frankf. Beitr. Didaktik Geogr. 5, 185-196 (1981).

19. Harden, C. P. Interrelationships between land abandonment and land degradation: a case from the Ecuadorian Andes. Mt. Res. Dev. 16, 274-280 (1996).

20. Curatola Fernández, G. F., Silva, B., Gawlik, J., Thies, B. \& Bendix, J. Bracken fern frond status classification in the Andes of southern Ecuador: combining multispectral satellite data and field spectroscopy. Int. J. Remote Sens. 34, 7020-7037 (2013)

21. Hartig, K. \& Beck, E. The bracken fern (Pteridium arachnoideum (Kaulf.) Maxon) dilemma in the Andes of Southern Ecuador. Ecotropica 9, 3-13 (2003).

22. Knoke, T., Stimm, B. \& Weber, M. Tropical farmers need productive alternatives. Nature 452, 934 (2008).

23. Beck, E. \& Richter, M. in The Tropical Mountain Forest: Biodiversity and Ecology Series 2 (eds Gradstein, S. R., Homeier, J. \& Gansert, D.) 195-217 (Universitätsverlag Göttingen, 2008).

24. Roos, K., Rödel, H. G. \& Beck, E. Short- and long-term effects of weed control on pastures infested with Pteridium arachnoideum and an attempt to regenerate abandoned pastures in South Ecuador. Weed Res. 51, 165-176 (2011).

25. Brauman, K. A., Daily, G. C., Ka'eo Duarte, T. \& Mooney, H. A. The Nature and value of ecosystem services: an overview highlighting hydrologic services. Annu. Rev. Environ. Resour. 32, 67-98 (2007).

26. Millennium Ecosystem Assessment. Ecosystems and Human Well-being: Synthesis (Island Press, C) 2005 World Resources Institute, 2005).

27. Daniel, T. C. et al. Contributions of cultural services to the ecosystem services agenda. Proc. Natl Acad. Sci. USA 109, 8812-8819 (2012).

28. Nelson, E. et al. Modeling multiple ecosystem services, biodiversity conservation, commodity production, and tradeoffs at landscape scales. Front. Ecol. Environ. 7, 4-11 (2009).

29. Goldstein, J. H. et al. Integrating ecosystem-service trade-offs into land-use decisions. Proc. Natl Acad. Sci. USA 109, 7565-7570 (2012).

30. Roos, K., Rollenbeck, R., Peters, T., Bendix, J. \& Beck, E. Growth of tropical bracken (Pteridium arachnoideum): response to weather variations and burning. Invasive Plant Sci. Manag. 3, 402-411 (2010).

31. Fries, A., Rollenbeck, R., Nauß, T., Peters, T. \& Bendix, J. Near surface air humidity in a megadiverse Andean mountain ecosystem of southern Ecuador and its regionalization. Agric. For. Meteorol. 152, 17-30 (2011).

32. Gholz, H. L., Ewel, K. C. \& Teskey, R. O. Water and forest productivity. Forest Ecol. Manag. 30, 1-18 (1990).

33. Silva, B. S. G. et al. Simulating canopy photosynthesis for two competing species of an anthropogenic grassland community in the Andes of southern Ecuador. Ecol. Model. 239, 14-26 (2012).

34. Kraft, P., Vaché, K. B., Frede, H. -G. \& Breuer, L. CMF: a hydrological programming language extension for integrated catchment models. Environ. Model. Softw. 26, 828-830 (2011).

35. Keeler, B. L. et al. Linking water quality and well-being for improved assessment and valuation of ecosystem services. Proc. Natl Acad. Sci. USA 109, 18619-18624 (2012)

36. Hamer, U., Potthast, K., Burneo, J. \& Makeschin, F. Nutrient stocks and phosphorus fractions in mountain soils of Southern Ecuador after conversion of forest to pasture. Biogeochemistry 112, 495-510 (2013).

37. Andrews, S. S., Karlen, D. L. \& Cambardella, C. A. The soil management assessment framework: a quantitative soil quality evaluation method. Soil Sci. Soc. Am. J. 68, 1945-1962 (2004).

38. Pulleman, M. et al. Soil biodiversity, biological indicators and soil ecosystem services-an overview of European approaches. Curr. Opin. Environ. Sustain 4, 529-538 (2012)

39. Makeschin, F., Haubrich, F., Abiy, M., Burneo, J. I. \& Klinger, T. in Gradients in a Tropical Mountain Ecosystem in Ecuador (eds Beck, E., Bendix, J., Kottke, I., Makeschin, F. \& Mosandl, R.) Ecological Studies 198, 397-408 (Springer, 2008).

40. Hamer, U., Potthast, K. \& Makeschin, F. Urea fertilisation affected soil organic matter dynamics and microbial community structure in pasture soils of Southern Ecuador. Appl. Soil Ecol. 43, 226-233 (2009).

41. Carú, M., Becerra, A., Sepúlveda, D. \& Cabello, A. Isolation of infective and effective Frankia strains from root nodules of Alnus acuminata (Betulaceae). World J. Microbiol. Biotechnol. 16, 647-651 (2000).

42. Knoke, T., Calvas, B., Ochoa, W. S., Onyekwelu, J. \& Griess, V. C. Food production and climate protection-What abandoned lands can do to preserve natural forests. Glob. Environ. Change 23, 1064-1072 (2013).

43. Knoke, T. et al. Effectiveness and distributional impacts of payments for reduced carbon emissions from deforestation. Erdkunde 63, 365-384 (2009).

44. Pohle, P., Gerique, A., Park, M. \& López Sandoval, M. F. in Tropical Rainforests and Agroforests Under Global Change (eds Tscharntke, T. et al.) 477-503 (Springer, 2010).

45. Bruijnzeel, L., Mulligan, M. \& Scatena, F. N. Hydrometeorology of tropical montane cloud forests: emerging patterns. Hydrol. Proc. 25, 465-498 (2011).
46. Windhorst, D., Kraft, P., Timbe, E., Frede, H.-G. \& Breuer, L. Stable water isotope tracing through hydrological models for disentangling runoff generation processes at the hillslope scale. Hydrol. Earth Syst. Sci. Discuss 11, 5179-5216 (2014).

47. Paulsch, D. \& Müller-Hohenstein, K. in Gradients in a Tropical Mountain Ecosystem of Ecuador (eds Beck, E., Bendix, J., Kottke, I., Makeschin, F. \& Mosandl, R.) Ecological Studies 198, 149-156 (Springer, 2008).

48. Turner, I. M. Species loss in fragments of tropical rain forest: A review of the evidence. J. Appl. Ecol. 33, 200-209 (1996).

49. Hilt, N. \& Fiedler, K. in Gradients in a Tropical Mountain Ecosystem of Ecuador (eds Beck, E., Bendix, J., Kottke, I., Makeschin, F. \& Mosandl, R.) Ecological Studies 198, 443-149 (Springer, 2008).

50. Homeier, J. et al. in Ecosystem Services, Biodiversity and Environmental Change in a Tropical Mountain Ecosystem of South Ecuador (eds Bendix, J. et al.) Ecological Studies 221, 93-106 (Springer, 2013).

51. Richter, M., Diertl, K. H., Emck, P., Peters, T. \& Beck, E. Reasons for an outstanding plant diversity in the tropical Andes of southern Ecuador. Landscape Online 12 (2009).

52. Pirard, R. \& Belna, K. Agriculture and deforestation: is REDD + rooted in evidence? For. Policy Econ. 21, 62-70 (2012).

53. de Koning, F. et al. Bridging the gap between forest conservation and poverty alleviation: the Ecuadorian Socio Bosque program. Environ. Sci. Policy 14, 531-542.

54. Knoke, T., Roman Cuesta, R. M., Weber, M. \& Haber, W. How can climate policy benefit from comprehensive land-use approaches? Front. Ecol. Environ 10, 438-445 (2012).

55. Potthast, K., Hamer, U. \& Makeschin, F. In an Ecuadorian pasture soil the growth of Setaria sphacelata, but not of soil microorganisms, is co-limited by $\mathrm{N}$ and P. Appl. Soil Ecol. 62, 103-114 (2012).

56. Bendix, J. et al. Model parameterization to simulate and compare the PAR absorption potential of two competing plant species. Int. J. Biometeorol. 54, 283-295 (2010).

57. Huwe, B., Zimmermann, B., Zeilinger, J., Quizhpe, M. \& Elsenbeer, H. in Gradients in a Tropical Mountain Ecosystem in Ecuador (eds Beck, E., Bendix, J., Kottke, I., Makeschin, F. \& Mosandl, R.) Ecological Studies 198, 375-386 (Springer, 2008).

58. Windhorst, D. et al.in Ecosystem Services, Biodiversity and Environmental Change in a Tropical Mountain Ecosystem of South Ecuador (eds Bendix, J. et al.) Ecological Studies 221, 275-286 (Springer, 2013).

59. Knoke, T., Steinbeis, O. E., Bösch, M., Román Cuesta, R. M. \& Burkhardt, T. Cost-effective compensation to avoid carbon emissions from forest loss: an approach to consider price-quantity effects and risk-aversion. Ecol. Econ. 70, 1139-1153 (2011).

60. Aguirre-Salado, C. A. et al. Mapping Leaf Area Index and canopy cover using hemispherical photography and spot 5 HGR data regression and K-NN. Agrociencia 45, 105-119 (2011).

61. Cabezas-Gutierrez, M. et al. Un modelo para la estimación del área foliar en tres especies forestales de forma no destructiva. Colombia Revista U.D.C.A Actualidad \& Divulgación Científica 12, 131-140 (2009).

62. Beck, E. et al. in Gradients in a Tropical Mountain Ecosystem in Ecuador (eds Beck, E., Bendix, J., Kottke, I., Makeschin, F. \& Mosandl, R.) Ecological Studies 198, 1-13 (Springer, 2008)

63. Günter, S. et al. Determinants for successful reforestation of abandoned pastures in the Andes: soil conditions and vegetation cover. Forest Ecol. Manag 258, 81-91 (2009).

64. Lawrence, D. M. et al. Parameterization improvements and functional and structural advances in version 4 of the community land model. J. Adv. Model. Earth Syst. 3 Art. 2011MS000045 (2011).

65. Bonan, G. B. et al. Improving canopy processes in the Community Land Model version 4 (CLM4) using global flux fields empirically inferred from FLUXNET data. J. Geophys. Res. 116, G02014 (2011).

66. Guswa, A. J. et al. Ecosystem services: challenges and opportunities for hydrologic modeling to support decision making. Water. Resour. Res 50, 4535-4544 (2014).

67. Qu, Y. \& Duffy, C. J. A semidiscrete finite volume formulation for multiprocess watershed simulation. Water Resour. Res. 43, W08419 (2007)

68. Bray, R. H. \& Kurtz, L. T. Determination of total, organic and available forms of phosphorus in soils. Soil Sci. 59, 39-45 (1945).

69. Vance, E. D., Brookes, P. C. \& Jenkinson, D. S. An extraction method for measuring soil microbial biomass C. Soil Biol. Biochem. 19, 703-707 (1987).

70. Hamer, U., Makeschin, F., Stadler, J. \& Klotz, S. Soil organic matter and microbial community structure in set-aside and intensively managed arable soils in NE-Saxony, Germany. Appl. Soil Ecol. 40, 465-475 (2008).

\section{Acknowledgements}

We thank the German Research Foundation (DFG) for financing the study (Research Units 402 and 816), Naturaleza y Cultura Internacional (Loja, San Diego) for support, our Ecuadorian partner Universities (UTPL, UNL Loja) for outstanding cooperation, 
the Ecuadorian Ministerio del Ambiente for granting research permits, the Ecuadorian Weather Service (INAMHI) for providing data from the stations Loja and San Ramon, and the staff of the Estación Científica San Francisco and many students and workers for their support. We also thank the farmers of Imbana, Los Guabos, El Tibio and Sabanilla for their contribution to this study. Finally, we are grateful to Laura Carlson for language editing.

\section{Author contributions}

T.K., E.B., J.B., P.P., L.B., R.M., M.W., B.S., S.G. and N.A. designed research and wrote the paper; P.H., U.H., A.G., M.L.S., K.R., A.T., B.S., B.C., L.M.C., D.W., X.P. and J.M. analysed data and performed research.

\section{Additional information}

Supplementary Information accompanies this paper at http://www.nature.com/ naturecommunications
Competing financial interests: The authors declare no competing financial interests.

Reprints and permission information is available online at http://npg.nature.com/ reprintsandpermissions/

How to cite this article: Knoke, T. et al. Afforestation or intense pasturing improve the ecological and economic value of abandoned tropical farmlands. Nat. Commun. 5:5612 doi: $10.1038 /$ ncomms6612 (2014).

(c) (i) This work is licensed under a Creative Commons Attribution 4.0 International License. The images or other third party material in this article are included in the article's Creative Commons license, unless indicated otherwise in the credit line; if the material is not included under the Creative Commons license, users will need to obtain permission from the license holder to reproduce the material. To view a copy of this license, visit http://creativecommons.org/licenses/by/4.0/ 